\title{
Research on the Impact Mechanism of Engineering Changes on Contract Price
}

\author{
Yaru Ren \\ School of Management, Tianjin University of Technology, Tianjin, 300384, China \\ Email: 825961522@qq.com
}

Keywords: Engineering Change, Contract Price, Oontract Status

\begin{abstract}
The complexity of project construction causes the uncertainty of the construction process, making the project change ubiquitous in the construction project, and engineering changes will lead to the contract price adjustment. Based on the analysis of the factors that caused the engineering change, the paper clearly defined the range of the factors that can cause the engineering change phenomenon, and then analyzed the adjustment factors of the contract state elements and the contract price, and established the association between them to explain the adjusting mechanism of the contract price so as to prevent the two parties from doing so. The issue is controversial and the efficiency of contract performance is improved.
\end{abstract}

\section{Analysis of Factors that Cause Project Change}

\subsection{Factors that cause engineering changes Identify}

To study the mechanism of impact of project changes on contract prices, first, it is necessary to clarify which factors will cause engineering changes. Contrast with the 1999 version of FIDIC, 56, 2013 version of the contract model can identify the factors that caused the project to change: Changes in the needs of the Employer, changes proposed by the Supervisor, work required to remedy deficiencies or damages caused by engineering implementation, any increase or decrease in work in the contract, or cancellation due to the additional work required to complete the work, the change in the amount of work contracted by both parties, Elevation and other basic parameters of the changes in order to make the project a success or failure to change the construction process or change the construction sequence, the progress of the project plan changes, non-contractors caused by the long-term suspension of construction, site conditions, abnormal abnormity climate change, the contractor Reasonable proposals, changes in laws and regulations, changes in the form of day-laborers, etc., to some extent, these factors can cause engineering changes.

\subsection{The factors that caused the project to change are classified}

According to the identified factors, there are many and complicated factors that cause engineering change. According to the different factors that cause the change, they are divided into design reasons, the reasons of the contractor, the reasons of the contractors, the reasons of the supervisors and the objective reasons.

There are many reasons for the project change. Basically, these five categories can be attributed to the analysis of the causes, which provide the most primitive analysis direction for determining the contract price and also play an important role in the control of the change. By identifying and classifying the factors influencing the change, the main body of responsibility in the implementation of the project can be distinguished, which plays an important role in determining and effectively controlling the change of project price.

\subsection{Analysis of Factors that Cause Project Change}

Based on the factors that have caused the engineering change, text analysis was used to analyze the involved factors. The method adopted is post-publication bias diagnosis method proposed by Zheng Hui-Lie [1], and the newer the publication time is, the larger its effect scale is. By analyzing the acquisition of the literature contents that can cause price adjustment in CNKI, Factor 
contribution score, CNKI collects the literature on engineering changes from 2008 to 2017 and draws from 15 articles that deal with the factors that cause engineering changes, and based on the analysis and based on the identification of the factors that caused the engineering changes, based on the principle that the closer the distance study proposed by Zheng Hui-Lie [1] is to the scale of its effect and the calculation and analysis of the formula proposed by him, the more important factors that cause engineering changes According to the order of their importance, the design plan is unreasonable, the contractor is mistaken, the conditions of the site are changed, the contractor is in error, the contractor's needs are changed, and the contractor is required to improve the quality.

Among them, due to the contractor's own errors caused, the contract price will not be adjusted. Based on this, this article will adjust the contract price due to the unreasonable design scheme, the change of site conditions, the failure of the employer, the change of the employer's requirement and the quality improvement of the contractor.

\section{Relationship between Contract Status and Contract Price}

\subsection{Definition of Elements of Construction Project Contract Status}

According to the scholars' analysis of the constitutional factors of the contract, the factors are summed up as five elements of the project quantity, construction conditions, construction scheme, construction period and contract price. The contract price is formed on the basis of the first four basic elements, and the first four elements are finally reflected in the form of affecting the contract price, thus forming a balance mechanism that affects each other. Finally, the contract state variables are summarized as the amount of engineering, construction conditions, construction programs and construction period.

According to the above analysis, we will match five factors that cause project changes with the elements of the contract status from the unreasonable design scheme, the change of site conditions, the failure of the employer, the change of the employer's requirement and the quality improvement of the outsourcer, as shown in Figure 1.

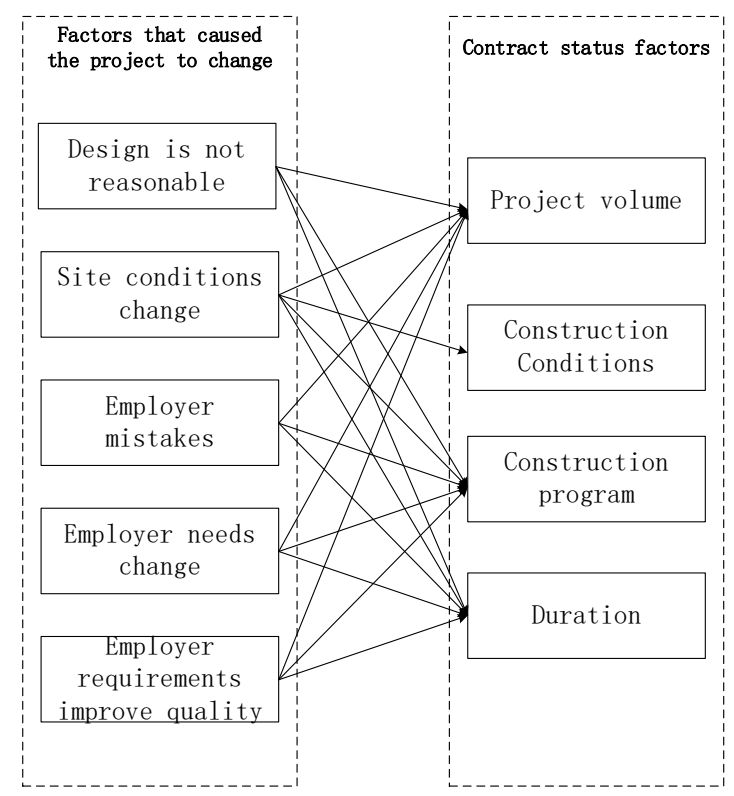

Figure.1. Changes in Contract Status Caused by Engineering Changes

\subsection{Deconstruction of Construction Project Contract Price Base}

\subsubsection{The nature of the contract price.}

The contract price is not a static concept. After the contract is signed, both parties have confirmed the expenses incurred for the project, but the price of the actual payment stage is not yet a kind of price that may change after payment of the contract. After the contractor completes the obligations stipulated in the contract, the Employer shall be obliged to pay the contractor for the 
corresponding price.

\subsubsection{Deconstruction of the contract price.}

The composition of construction and installation cost specifications issued by the Ministry of Finance in 2013 will make up its cost composition for further WBS decomposition. After analysis, the contract price will be deconstructed layer by layer, and the comprehensive unit price, construction quantity, Rate a total of five project price adjustment object. Among them, the provincial or municipal departments or industry departments directly stipulate the rate of calculating the total price of the total price, and the value of the rate has a relationship with the factors that affect the status of the contract. Therefore, the integrated unit price, the project amount, the total price of the remaining four factors and the calculation basis are This article analyzes the contract price adjustment object.

\subsection{The relationship between contract status and contract price}

The following analysis of the contract conditions of the basic conditions of the contract price factors, including the construction program, construction conditions, duration and quantity.

(a) Impact of Construction Scheme on Contract Price.

(b) The impact of construction conditions on the contract price.

(c) The impact of the construction period on the contract price.

(d) Impact of construction volume on contract price.

In summary, the basic conditions of the contract status of the contract price impact mainly through the realization of its basic components, shown in Figure2.

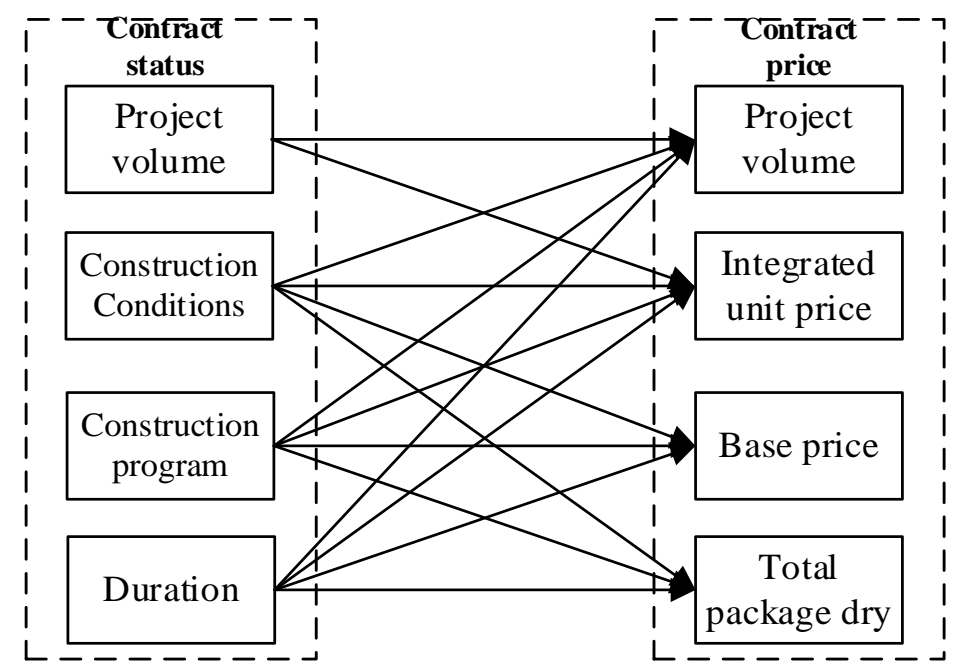

Figure.2. The basic conditions of contract status and contract price components between the mapping

\section{Impact of Engineering Change on Contract Price}

\subsection{The basic model of contract status change}

Based on GHM model and contract price adjustment caused by engineering change, this paper constructs a model of contract status change: Suppose that both parties signed a construction contract in the date of 0 , agreed that the contractor provided the contractor with a specific Construction products; it is estimated that on the date of the 1st period, the contractor submits the agreed construction products to the Employer according to the standard agreed upon in stage 0, and the Employer shall pay the contractor for the contracted project cost as stipulated in Phase 0. Based on the bounded rationality of human beings, the complexity of the implementation environment and the asymmetry of information, the contract signed by contractor in phase 0 is not complete. Some changes have taken place between stages 0 and 1, That is, the factors that caused the project to change, resulting in the project actually arrived at the first phase, the actual state and the expected 
state of the contract deviated beyond the scope of the contract agreed in the 0 period, the need to negotiate the contract by both parties, That is, the contract price adjustment, to the 0 period of the contract to modify and supplement, so as to achieve the contract state balance 2, shown in Figure 3.

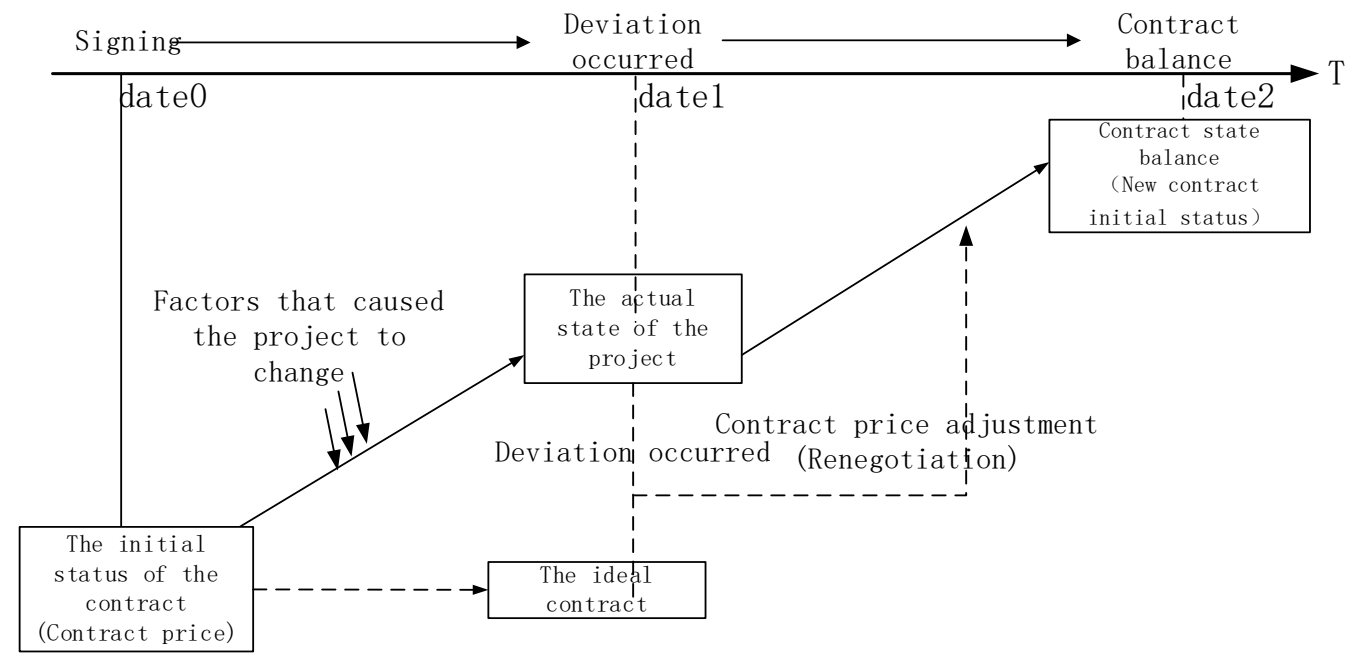

Figure.3. Model of Contract Status Change

\subsection{Model Evolution of Contract Status Change}

According to the above analysis, the relationship between the project change and the contract status, the contract status and the contract price will be combined to get a total mapping relationship between the three, as shown in Figure4.

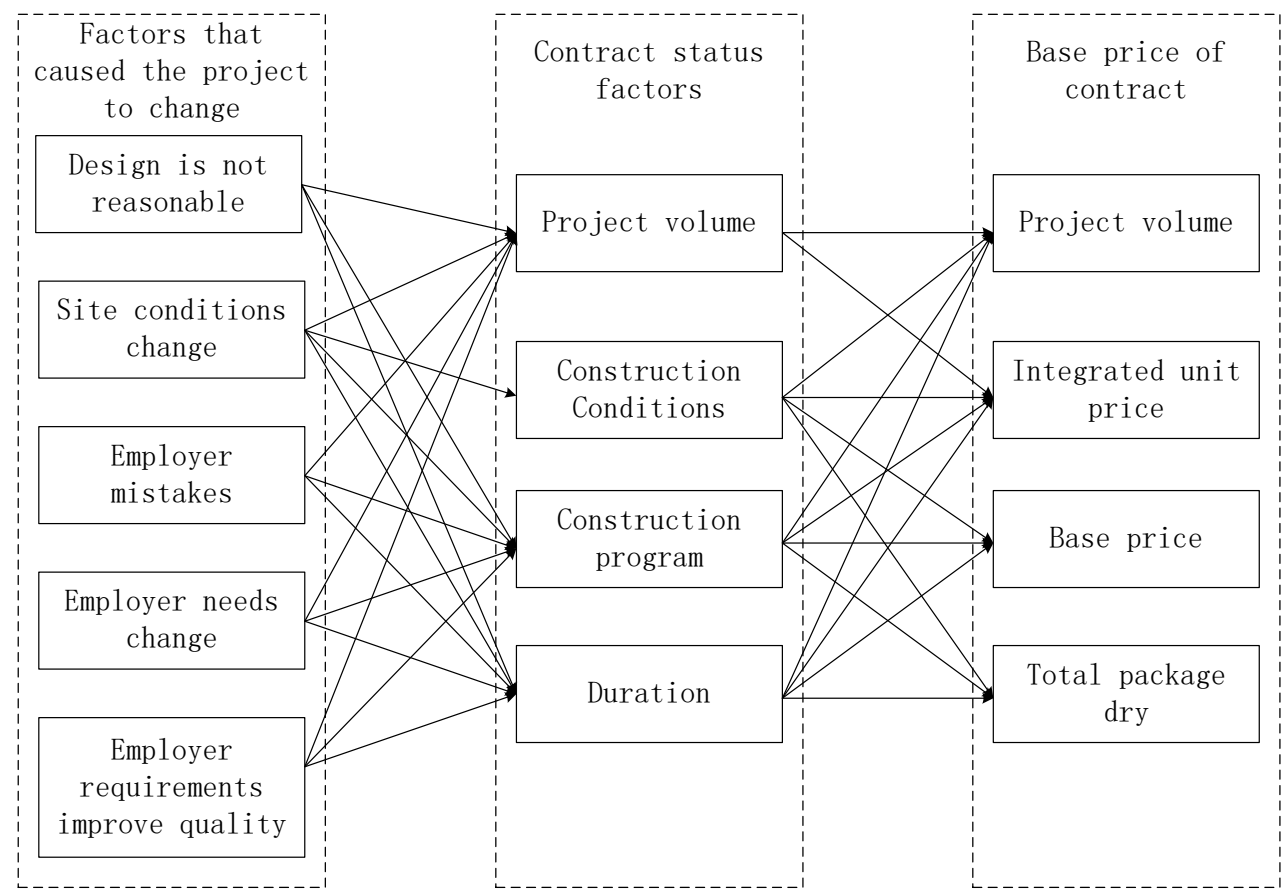

Figure.4. Change, contract status and price mapping diagram

Based on the model in Figure 3 and the mapping in Figure 4, the contract state change model is evolved to build a new balance model, shown in Figure 5, and compared with Hart's GHM model and the earliest proposed contractual model, shows how the engineering change caused the construction contract price adjustment. 


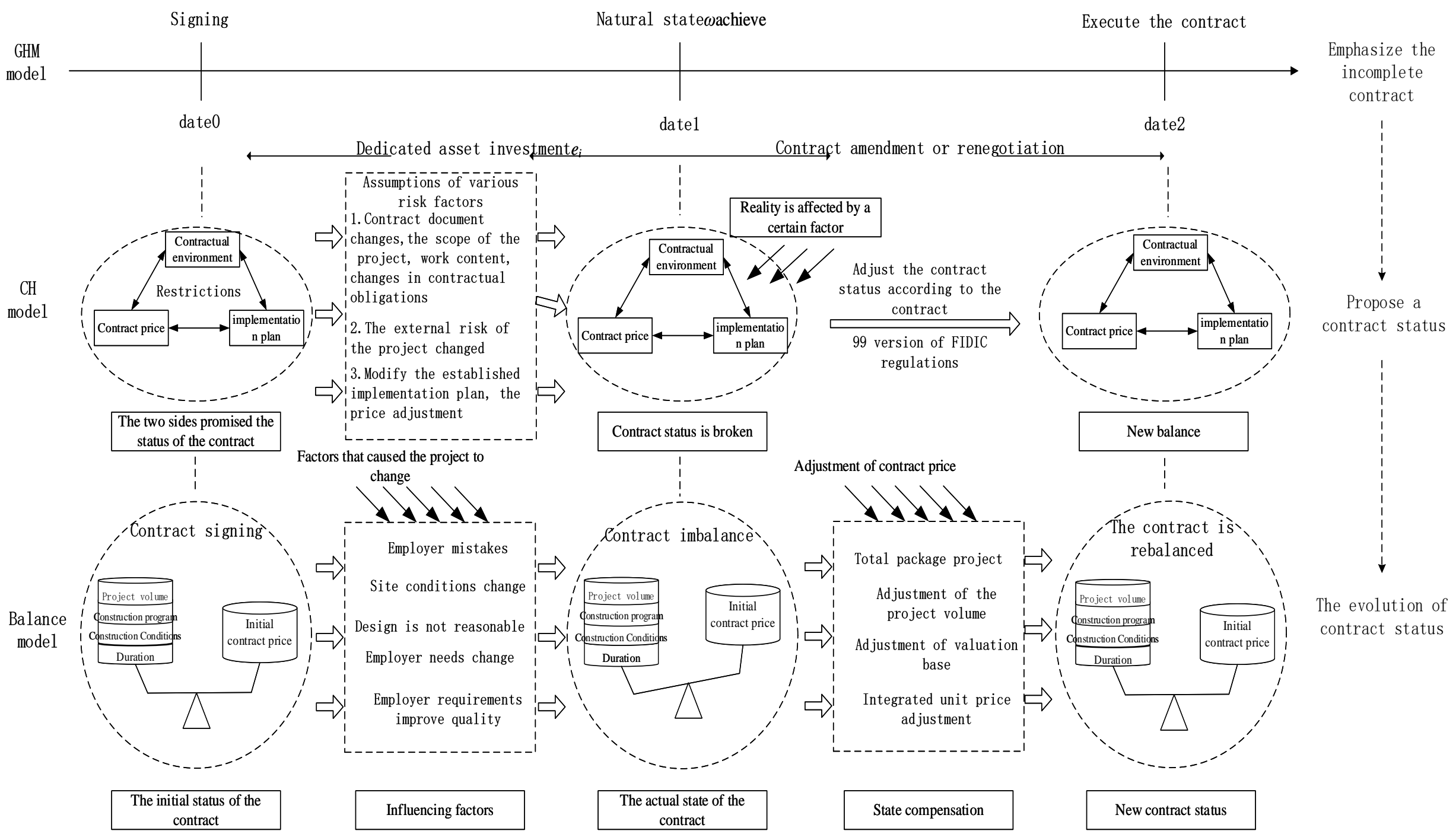

Figure.5. Schematic diagram of the impact mechanism of construction contract price adjustment caused by engineering change 
Figure 5 shows the evolution of the contract state model. First proposed by Hart et al GHM model, described in the contracting phase (date0) due to the future natural state $\omega$ can not determine the full contract can not be signed, in order to protect the ultimate benefit, the introduction of proprietary funds ei, until the project reached its natural state (date 1), some kind of cost-free operation based on the benefit of both parties and finally reaching the final stage (date 2). Hart, etc. through the model shows that the contract is not complete.

Cheng $\mathrm{Hu}$ analyzed the forming process of the contract and proposed that the contract price means that the contractor should, according to the stipulations of the contract, adopt the planned scheme in a specific environment to fulfill the payment of the contractor that should be obtained from the contract. And he will contract price, contract documents, the environment and the implementation of these four factors are linked to each other, influence each other based on the composition of the whole called the contract status. And affected by changes in contract documents, changes in the environment and changes in the implementation plan, the reality can be adjusted according to the relevant provisions so that the state can reach a new balance.

Based on the research perspective of engineering change, based on the research model of Chenghu, this paper extends the identified elements of the contract state through the construction of the model and the mapping relationship based on the changes, contract states and contract price basis established, Contract State Model - Balance Model. From the analysis of the change of contract status during the implementation of the entire project, as shown in Figure 5, it can be seen that the balanced contract status will be broken and the contract is unbalanced when the risk factors causing the project change appear. At this point, the need to adjust the project price to make the contract state to a new balance [2]. The reason is that the risk factors have affected the pricing basis of construction contract price, and the rights and obligations of both parties need to be adjusted. By adjusting the unit price, adjusting the project volume, adjusting the basis of valuation and adjusting the total contract price, the unbalanced contract status compensation can make the contract reach a new equilibrium. This new balance status is also the initial contract status of the next contract status compensation, so constantly breaking, compensation cycle to the end of the project. In this way, we can explain the inherent mechanism of contract price adjustment caused by engineering change.

\section{Conclusions}

First of all, based on the method of reference analysis of Zheng Hui-Lie, we choose the unreasonable design plan, the change of the site conditions, the failure of the contractor, the change of the contractor's requirement and the request of the contractor to improve the quality. Five more important factors in-depth analysis. Secondly, based on the research on contract status proposed by a large number of scholars after Cheng Hu was put forward, the relationship between the factors causing the change and the elements of contract status was obtained. And because of the impact of the contract status and the contract price, the influencing factors of the contract price are first deconstructed and the mapping relationship with the contract status elements is analyzed. Finally, based on the mapping relationship between change, contract status and price, the contractual status of Cheng hu is evolved to build a contract state evolution model, which explains the inherent mechanism of contract price adjustment caused by engineering change.

\section{References}

[1] Zheng Hui-Lie. Publish time-based publication bias diagnosis method [D]. Wuhan: Huazhong University of Science and Technology, 2010.

[2] Chen Jing. Study on the effect and adjustment of the contract error caused by engineering quantity deviation based on state compensation [D]. Tianjin: Tianjin University of Technology, 2014. 